\title{
Scaffolds Derived from ECM Produced by Chondrogenically Induced Human MSC Condensates Support Human MSC Chondrogenesis
}

\author{
Anna D. Dikina, ${ }^{\dagger}$ Henrique V. Almeida, ${ }^{\ddagger}, \S, \bigcirc$ Meng Cao, ${ }^{\dagger}$ Daniel J. Kelly, ${ }^{\ddagger}, \S, \|, \perp$ and Eben Alsberg ${ }^{*}, \dagger, \#, \nabla_{0}$ \\ ${ }^{\dagger}$ Department of Biomedical Engineering, Case Western Reserve University, 10900 Euclid Avenue, Cleveland, Ohio 44106, United \\ States \\ ${ }^{\ddagger}$ Trinity Centre for Bioengineering, Trinity Biomedical Sciences Institute, Trinity College Dublin, 152-160 Pearse Street, Dublin 2, \\ Ireland \\ ${ }^{\S}$ Department of Mechanical and Manufacturing Engineering, School of Engineering, Trinity College Dublin, College Green, Dublin 2, \\ Ireland \\ "Tissue Engineering Research Group, Department of Anatomy, Royal College of Surgeons in Ireland, 123 St. Stephen’s Green, \\ Dublin 2, Ireland \\ ${ }^{\perp}$ Advanced Materials and Bioengineering Research Centre (AMBER), Trinity College Dublin \& Royal College of Surgeons in Ireland, \\ Dublin 2, Ireland \\ \#Orthopaedic Surgery, Case Western Reserve University, 10900 Euclid Avenue, Cleveland, Ohio 44106, United States

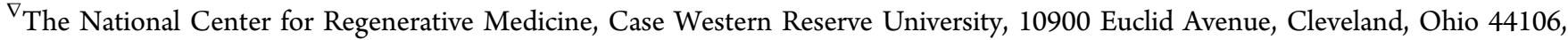 \\ United States
}

\section{Supporting Information}

ABSTRACT: Osteoarthritis is a leading cause of disability affecting an increasing number of individuals. However, cartilage replacement therapies are inadequate, and better cartilage regeneration products must be developed. In this work, we describe a human mesenchymal stem cell (hMSC)-based approach for fabricating extracellular matrix (ECM) scaffolds from tissueengineered cartilage sheets and then for inducing chondrogenesis of reseeded hMSCs within the ECM scaffolds. Two types of ECM scaffolds were fabricated: one from high-density hMSC sheets cultured with media-supplemented transforming growth factor beta- 1 (TGF- $\beta 1$; $-\mathrm{MS}$ ) and the other from high-density hMSC sheets incorporated with TGF- $\beta 1$-laden gelatin microspheres (+MS), which significantly enhance chondrogenesis within the sheet system. Interestingly, when scaffolds were reseeded with hMSCs, -MS scaffolds lead to significantly more glycosaminoglycan (GAG) accumulation than +MS scaffolds. Importantly, ECM scaffolds could be soak loaded with TGF- $\beta 1$ to produce cartilage of similar quality as that of constructs cultured with TGF- $\beta 1$ in the media, thereby removing the need for supplementing the media with the growth factor. Lastly, tissues formed with the scaffolds were larger with more uniform cartilage matrix elaboration compared to scaffold-free groups making this strategy a clinically promising auto- or allogeneic therapy.
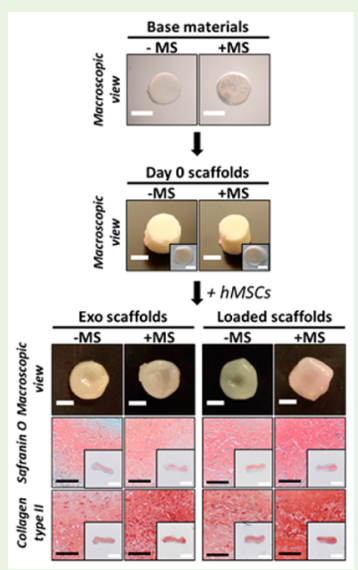

KEYWORDS: tissue engineering, cartilage, decellularized, biomaterials, human mesenchymal stem cells, microspheres

\section{INTRODUCTION}

Articular cartilage lines the ends of bones and serves an important function in proper joint performance by providing a weight-bearing and low-friction surface. The significance of articular cartilage is highlighted by its ability to greatly affect day-to-day life when damaged. Even focal lesions in cartilage can cause pain and reduced mobility ${ }^{1,2}$ and may ultimately lead to broader joint degeneration. ${ }^{3}$ In addition, cartilage is avascular and has relatively few cells resulting in minimal capacity for selfrepair. ${ }^{1}$ For these reasons, osteoarthritis is a leading cause of disability. ${ }^{4}$ In 2005, approximately 27 million Americans had osteoarthritis, ${ }^{5}$ and this number is expected to grow to 59 million by $2020^{6}$ creating a forecasted $\$ 9$ billion total knee and hip replacement market and an additional $\$ 460$ million tissue- engineered and cell therapy-based cartilage product market in the US alone. ${ }^{7}$ Short of total joint replacement, existing strategies such as microfracture, mosaic arthroplasty, and autologous chondrocyte implantation (ACI) are inadequate as they often integrate poorly with the native cartilage, form tissue with inferior mechanical properties, and/or lead to further joint degeneration. ${ }^{1,8-10}$ As result, new tissue engineering strategies for cartilage regeneration are being explored.

Special Issue: Biomimetic Bioactive Biomaterials: The Next Generation of Implantable Devices

Received: October 21, 2016

Accepted: January 24, 2017

Published: January 24, 2017 
One promising approach for engineering replacement cartilage is through the use of cartilage-derived extracellular matrix materials. ${ }^{11-13}$ In this strategy, the immune response of the recipient of these materials should be minimized or avoided by removing allogeneic or xenogeneic cellular material from the tissue while maintaining the composition of the ECM, whose constituents are conserved within species and well-tolerated across species. ${ }^{14}$ Cells may be seeded into scaffolds fabricated from the ECM or mixed with ECM particles to create a permissive environment or to drive cartilage tissue formation. This strategy takes advantage of the natural biochemical and physical cell-signaling properties of the ECM, a threedimensional network of proteins, glycosaminoglycans, proteoglycans, and glycoproteins which normally envelopes cells and can regulate their behaviors including attachment, proliferation, and differentiation. ${ }^{15}$ In addition to their inherent properties, scaffolds composed of cartilaginous ECM may be altered to enhance their mechanical properties ${ }^{16}$ and to serve as bioactive factor delivery depots. ${ }^{17,18}$ While native cartilage tissue ECM has been extensively explored in its ability to drive chondrogenesis, in vitro cell-derived ECM presents certain advantages. ${ }^{19}$ First, autologous extracellular matrix-based scaffolds can only be fabricated from cultured cell-derived tissues as there are currently no tissue banks for autologous cartilage. An autologous therapy avoids the risk of disease transmission and immune rejection, which may occur with cadaveric tissue. ${ }^{11}$ Second, it may also be possible to use cell-derived matrices in allogeneic therapy because it is generally easier to remove cellular material from tissue-engineered constructs than from dense native cartilage ${ }^{12}$ and because allogeneic stem cellderived matrices may not elicit an immune response in a cartilage setting. ${ }^{20}$ Lastly, tissue engineered materials for production of ECM scaffolds can be customized by controlling their composition (e.g., cells and biomaterials) and culture conditions (e.g., growth factors and mechanical stimuli).

A stem cell source, such as mesenchymal stem cells (MSCs), for both engineering cartilaginous ECM from which scaffolds are produced as well as reseeding the scaffolds, is beneficial over the use of mature chondrocytes. Stem cell therapies avoid the invasive cartilage harvest that is necessary to acquire chondrocytes and its associated complications. ${ }^{22}$ MSCs can be isolated from a patient's bone marrow aspirate, which is obtained in a minimally invasive procedure. Unlike chondrocytes, MSCs can be easily culture expanded without losing their phenotype $\mathrm{e}^{23}$ and subsequently differentiated to induce the formation of cartilage tissue. ${ }^{24,25}$ Additionally, chondrogenically induced MSC-derived ECM has the potential to be more chondroinductive than chondrocyte-derived ECM when reseeded with MSCs. ${ }^{26}$ This may be because mature cartilage ECM, which has a different composition from immature cartilage, may not contain the appropriate signals necessary to drive the natural chondrogenic differentiation of MSCs. ${ }^{27-29}$

In this work, we explored the chondrogenic potential of ECMs derived from MSC-based engineered neocartilage. Our group has previously developed a robust system for engineering cartilage from scaffold-free, high-density human MSCs (hMSCs)..$^{21-27}$ Specifically, hMSC constructs incorporated with chondrogenic transforming growth factor beta-1 (TGF$\beta 1$ )-loaded gelatin microspheres (MS) have been used for fabrication of cartilaginous pellets, ${ }^{26,27}$ sheets, ${ }^{22,23}$ and rings and tubes. $^{24,25}$ The use of controlled TGF- $\beta 1$ presentation from within the high-density tissues formed by marrow-derived hMSCs enhanced chondrogenesis with more cartilaginous
ECM production that was better distributed compared to that of standard cultures with TGF- $\beta 1$ supplied in the media. In the current study, cartilage engineered with TGF- $\beta 1$-loaded MS and standard hMSC culture with exogenous TGF- $\beta 1$ in the media were used to create ECM scaffolds. We also investigated the potential of these ECMs to serve as TGF- $\beta$ 1-presenting vehicles so that media supplementation of growth factor can be avoided when hMSCs are seeded back into the ECM scaffolds. To our knowledge, this is the first report of three-dimensional ECM scaffolds formed from chondrogenically differentiated high-density hMSC scaffold-free tissues to support cartilage formation by reseeded hMSCs ${ }^{27,37,38}$ and employed for growth factor presentation to further promote hMSC-based chondrogenesis. This study takes steps toward engineering a chondrogenic scaffold derived from natural materials for the creation of an off-the-shelf cartilage replacement product.

\section{METHODS}

hMSC Isolation and Culture. Under the approval of University Hospitals of Cleveland Institutional Review Board, mononuclear cells were isolated from whole bone marrow of healthy patients (female 27 yrs and male 28 yrs; Case Comprehensive Cancer Center Hematopoietic Biorepository and Cellular Therapy Core) using a Percoll gradient (Sigma-Aldrich, St. Louis, MO). ${ }^{31}$ Adherent cells (hMSCs) were cultured in Dulbecco's modified Eagle's medium-low glucose (DMEM-LG; Sigma-Aldrich) containing 10\% prescreened fetal bovine serum (Gibco Qualified FBS; Life Technologies, Carlsbad, CA or Sigma Premium FBS; Sigma-Aldrich), ${ }^{32}$ and $10 \mathrm{ng} / \mathrm{mL}$ fibroblast growth factor-2 (FGF-2, R\&D Systems, Minneapolis, MN). Passage 3 cells from 2 donors were used in this study: one donor's cells produced the tissue for making the scaffolds, and the other donor's cells were seeded into the scaffolds to mirror a therapy which combines an allogeneic "off-the-shelf" product with autologous cells for treatment of a cartilage defect.

Production of Tissue Engineered Cartilage Sheets to Obtain Scaffold "Base Material". High-density hMSC tissue engineered sheets with and without TGF- $\beta$ 1-loaded microspheres ${ }^{22}$ were used as the "base material". Briefly, cross-linked gelatin microspheres were loaded with $400 \mathrm{ng}$ of TGF- $\beta 1$ (PeproTech, Rocky Hill, NJ) per mg microspheres for $2 \mathrm{~h}$ at $37^{\circ} \mathrm{C}$. Prior to seeding cells, cell culture inserts (12 mm diameter in 12-well plates; Corning Inc., Corning, NY) were incubated with $0.75 \mathrm{~mL}$ of DMEM-LG containing $10 \% \mathrm{FBS}$ in each plate well for $2 \mathrm{~h}$ at $37^{\circ} \mathrm{C}$. After the incubation, an additional $0.75 \mathrm{~mL}$ of basal pellet medium (BPM) comprising Dulbecco's modified Eagle's medium-high glucose (DMEM-HG; Sigma-Aldrich), 1\% ITS+ Premix (Corning Inc.), $10^{-7} \mathrm{M}$ dexamethasone (MP Biomedicals, Solon, $\mathrm{OH}), 1 \mathrm{mM}$ sodium pyruvate (GE Healthcare Life Sciences, Logan, UT), $100 \mathrm{mM}$ nonessential amino acids (Lonza Group, Basel, Switzerland), $37.5 \mathrm{mg} / \mathrm{mL}$ ascorbic acid-2-phosphate (Wako Chemicals USA Inc., Richmond, VA), and $100 \mathrm{U} / \mathrm{mL}$ penicillinstreptomycin (Corning Inc.) was added to each plate well. Two million $\left(2 \times 10^{6}\right) \mathrm{hMSCs}$ and microspheres $\left(0.75 \mathrm{mg} / 10^{6} \mathrm{hMSCs}\right)$ in $500 \mu \mathrm{L}$ of BPM were seeded onto the cell culture inserts to make microsphere-containing sheets ("+MS"). On day 1 , the media in the plate wells was replaced with $1.5 \mathrm{~mL}$ of BPM per well. A complete media change $(2 \mathrm{~mL})$ occurred $48 \mathrm{~h}$ after cell seeding and every other day subsequently. Sheets without microspheres ("-MS") were prepared and cultured in the same manner, except that BPM was supplemented with $10 \mathrm{ng} / \mathrm{mL}$ TGF- $\beta 1$. Both types of sheets were cultured for 4 weeks.

Scaffold Fabrication. Tissue engineered cartilage sheets (base materials) were used for scaffold fabrication ("day 0 scaffolds"). Sheets were harvested aseptically after 4 weeks of culture and frozen at -20 ${ }^{\circ} \mathrm{C}$. Frozen sheets were sent on dry ice to Trinity College Dublin for scaffold fabrication as previously described. ${ }^{18}$ Briefly, tissues were minced with a scalpel and then pulverized in a cryogenic mill (6770 Freezer/Mill, SPEX, UK). A fine cartilage slurry in sterile Type 1 water $(250 \mathrm{mg} / \mathrm{mL})$ was prepared using a homogenizer (IKAT10, IKA 


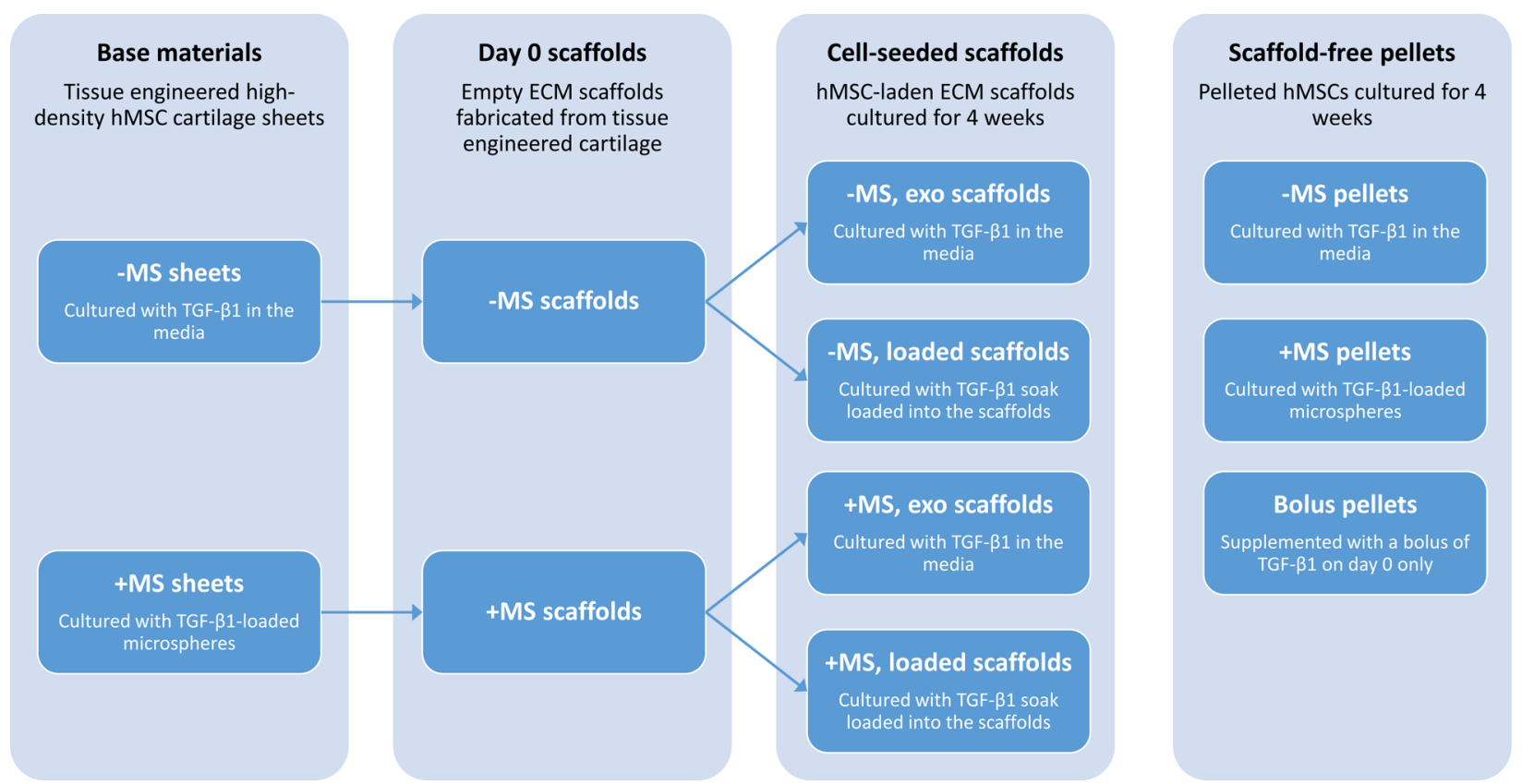

Figure 1. Outline of the experimental groups, the distinctive conditions used to create them, and their relationships to each other.

Works, Wilmington, NC). Then, $60 \mu \mathrm{L}$ of slurry $(15 \mathrm{mg})$ was freezedried (FreeZone Triad, Labconco, Kansas City, MO) in custom-made polycarbonate molds $(5 \mathrm{~mm}$ diameter, $3 \mathrm{~mm}$ height) under a controlled temperature profile: cooled to $-30^{\circ} \mathrm{C}\left(-1{ }^{\circ} \mathrm{C} / \mathrm{min}\right)$, held at $-30{ }^{\circ} \mathrm{C}(1 \mathrm{~h})$, warmed to $-10{ }^{\circ} \mathrm{C}\left(+1{ }^{\circ} \mathrm{C} / \mathrm{min}\right)$, held at $-10{ }^{\circ} \mathrm{C}(24$ $\mathrm{h})$, and warmed to room temperature $\left(\mathrm{RT} ;+0.5^{\circ} \mathrm{C} / \mathrm{min}\right)$. Next, the material was cross-linked via a dehydrothermal (DHT) technique using a vacuum oven (VD23, Binder, Germany; $115^{\circ} \mathrm{C}, 2$ mbar, $24 \mathrm{~h}$ ) to form porous scaffolds. DHT-cross-linked scaffolds were shipped at RT to Case Western Reserve University. Scaffolds were further crosslinked in a solution of $15.6 \mathrm{mM} \mathrm{1-(3-(Dimethylamino)propyl)-3-}$ ethylcarbodiimide hydrochloride (EDC, ProteoChem, Cheyenne, $\mathrm{WY}$ ) and $6.1 \mathrm{mM} \mathrm{N}$-hydroxysuccinimide $98+\%$ (NHS, Fisher Scientific, Pittsburgh, PA) for $2 \mathrm{~h}$ at RT and then washed twice with PBS for $30 \mathrm{~min}$ at RT on an orbital shaker (30 rpm). Aseptic conditions were maintained throughout scaffold fabrication.

Production of Cell-Seeded Scaffolds and Scaffold-Free Controls. Scaffolds were placed in $5 \mathrm{~mm}$ diameter $3 \%$ agarose (Denville Scientific Inc., Metuchen, NJ) wells. Some $-\mathrm{MS}$ and +MS scaffolds were seeded with $0.5 \times 10^{6} \mathrm{hMSCs}$ in $40 \mu \mathrm{L}$ of BPM containing $0.4 \mathrm{ng}$ of TGF- $\beta 1$ ( $10 \mathrm{ng}$ of TGF- $\beta 1 / \mathrm{mL}$ BPM) and received the same TGF- $\beta 1$ supplementation (10 ng TGF- $\beta 1 / \mathrm{mL}$ ) exogenously in the culture medium at every feeding ("exo scaffolds"). In the "loaded scaffolds" groups, $0.5 \times 10^{6} \mathrm{hMSCs}$ in $40 \mu \mathrm{L}$ of BPM containing $150 \mathrm{ng}$ of TGF- $\beta 1$ (3.75 $\mu \mathrm{g}$ TGF- $\beta 1 / \mathrm{mL}$ BPM) were seeded into - MS and + MS scaffolds so that TGF- $\beta 1$ would be released from the scaffold. Therefore, BPM without additional TGF- $\beta 1$ was used as the culture medium for loaded scaffolds. After $2 \mathrm{~h}, 2.5 \mathrm{~mL}$ of condition-specific culture medium was added to each well. As a result, the TGF- $\beta 1$ concentration regimen for loaded scaffolds was as follows: $2 \mathrm{~h}$ at $3.75 \mu \mathrm{g} / \mathrm{mL}$ followed by $60 \mathrm{ng} / \mathrm{mL}$ until the first media change with BPM without TGF- $\beta 1$ on day 3 .

In a separate experiment, three groups of scaffold-free controls (scaffold-free pellets) were fabricated using the same hMSC donor and passage and cultured: (1) pellets without microspheres (-MS) were formed and cultured with continuous TGF- $\beta 1$ supplementation (10 ng TGF- $\beta 1 / \mathrm{mL}$ BPM), (2) pellets containing TGF- $\beta 1$-loaded microspheres $(+\mathrm{MS})$, which were prepared the same way as in the $+\mathrm{MS}$ base material sheets (400 ng TGF- $\beta 1 / \mathrm{mg}$ microsphere, $0.75 \mathrm{mg}$ microspheres $/ 10^{6}$ hMSCs), were formed and cultured in BPM without TGF- $\beta 1$, and (3) pellets receiving a bolus TGF- $\beta 1$ treatment on day 0 only (bolus) received $150 \mathrm{ng}$ of TGF- $\beta 1 / 40 \mu \mathrm{L}$ BPM during pellet formation and were further cultured in BPM without TGF- $\beta 1$.
Scaffold-free pellets were made by centrifuging $(500 \mathrm{~g}, 5 \mathrm{~min}) 0.5 \times 10^{6}$ hMSCs in $40 \mu \mathrm{L}$ of BPM with $10 \mathrm{ng}$ of TGF- $\beta 1 / \mathrm{mL}$ BPM for the -MS group, with TGF- $\beta 1$-loaded microspheres for the +MS group, or with $150 \mathrm{ng}$ TGF- $\beta 1$ for the bolus group in a 96 -well plate (Greiner bio-one, Monroe, North Carolina). This was done because scaffoldfree pellets could not form well in the $5 \mathrm{~mm}$ agarose wells. After $2 \mathrm{~h}$, $160 \mu \mathrm{L}$ of condition-specific medium was added to the pellets. After 24 $\mathrm{h}$, the scaffold-free controls and the $200 \mu \mathrm{L}$ medium in which they were formed were transferred into agarose wells containing $2.3 \mathrm{~mL}$ of condition-specific media. The total media volume was then $2.5 \mathrm{~mL}$ so that their culture conditions were the same as those of cell-laden scaffolds. The TGF- $\beta 1$ concentration regimen for bolus scaffold-free pellets was as follows: $2 \mathrm{~h}$ at $3.75 \mu \mathrm{g} / \mathrm{mL}$ followed by $22 \mathrm{~h}$ at $750 \mathrm{ng} /$ $\mathrm{mL}$ and then $60 \mathrm{ng} / \mathrm{mL}$ until the first media change with BPM without TGF- $\beta 1$ on day 3 .

Individual agarose wells containing each construct (exo scaffolds, loaded scaffolds, and scaffold-free pellets) were cultured in 12 well plates (Corning Inc.) for 4 weeks with media changes $(2.5 \mathrm{~mL})$ twice each week. Figure 1 presents all of the experimental groups and outlines their relationships.

Biochemical Analysis. Sheets used for scaffold fabrication $(3 \mathrm{~mm}$ diameter punch, $N=3)$, day 0 scaffolds without cells $(N=4)$, cellseeded scaffolds $(N=4)$, and scaffold-free controls $(N=4)$ were digested in papain solution (Sigma-Aldrich) at $65{ }^{\circ} \mathrm{C}^{33} \mathrm{GAG}$ was quantified via the dimethylmethylene blue assay (DMMB; SigmaAldrich). ${ }^{34}$ DNA was measured with the PicoGreen assay (Invitrogen, Carlsbad, CA). ${ }^{35}$ GAG and DNA contents of cellular constructs were normalized to the wet weight of the tissue at harvest.

Histology and Immunohistochemistry. Sheets used for scaffold fabrication $(N=3)$, day 0 scaffolds without cells $(N=4)$, cell-seeded scaffolds $(N=4)$, and scaffold-free controls $(N=4)$ were fixed in $10 \%$ neutral buffered formalin and paraffin embedded. Some tissues were sectioned through the thickness of the tissue in a vertical plane. Other tissues were sectioned in a nonvertical, randomly oriented plane. Mounted tissue sections $(5 \mu \mathrm{m})$ were stained with hematoxylin (Fisher HealthCare, Fisher Scientific) and eosin (Richard-Allan Scientific, ThermoFisher Scientific, Waltham, MA) (H\&E), Safranin O (Acros Organics, Fisher Scientific) for sulfated GAG content, anticollagen type II primary antibody (abcam ab34712, Cambridge, UK), and anticollagen type I primary antibody (abcam ab21287). Fast Green (Fisher Scientific) counterstain was used for the Safranin O and collagen types I and II staining. ${ }^{24}$ 
Image Acquisition. Macroscopic pictures of base material sheets ( $3 \mathrm{~mm}$ punch) and hydrated day 0 scaffolds were taken on a stereo microscope (Nikon SMZ-10, Tokyo, Japan) mounted with a Coolpix 995 camera (Nikon). Images of dry day 0 scaffolds, cell-seeded exo and loaded scaffolds, and scaffold-free pellets were taken with a phone camera (Galaxy S4 and S5, Samsung, Seoul, South Korea). An Olympus BX61VS microscope (Olympus, Center Valley, PA) equipped with a Pike F-505 camera (Allied Vision Technologies, Stadtroda, Germany) was used to capture images of stained tissue sections.

Mechanical Analysis. Cell-seeded scaffolds $(N=3-4)$ were evaluated in unconfined compression based on previously described methods. ${ }^{18}$ Briefly, frozen constructs were thawed in PBS at RT containing $0.1 \%$ protease inhibitor (Sigma-Aldrich) for $30 \mathrm{~min}$. A preload of $0.03 \mathrm{~N}$ was applied for $500 \mathrm{~s}$ using an R Series Controller mechanical testing device (Test Resources Inc., Shakopee, MN). Constructs were then compressed to $10 \%$ strain at $0.001 \mathrm{~mm} / \mathrm{s}$. Equilibrium load was recorded after $30 \mathrm{~min}$ of stress relaxation. An equilibrium modulus was calculated by dividing the equilibrium load by the cross-sectional area of the construct determined via analysis of macroscopic images of the constructs (ImageJ, NIH).

Statistical Analysis. All samples were analyzed using one-way ANOVA with Tukey's post hoc tests when $p<0.05$ (InStat 3.06, GraphPad Software Inc., La Jolla, CA). Reported values are the mean \pm standard deviation.

\section{RESULTS}

Base Material and Empty Scaffold Characterization. The base materials for fabricating the cell-derived ECM scaffolds were derived from high-density hMSC sheets stimulated to form engineered cartilage tissue. Cellular sheets made from hMSCs with TGF- $\beta 1$ in media ( - MS) or hMSCs with TGF- $\beta 1$-loaded microspheres (+MS) and cultured for 4 weeks resulted in tissue engineered cartilaginous base materials (Figure 2). Sheets were easy to handle; however, unlike previous reports ${ }^{22,23}$ they were semitranslucent and could fold upon themselves, likely due to donor and serum variability. Macroscopic images of sheets (3 $\mathrm{mm}$ diameter punch) revealed some undegraded microspheres giving the +MS sheets heterogeneous coloring (Figure 2A). H\&E staining (Figure 2B) depicted the presence of basophilic structures supported by strong Safranin O staining for GAG in both $-\mathrm{MS}$ and $+\mathrm{MS}$ constructs (Figure 2C). Both engineered tissues stained positively for collagen type II (Figure 2D). Microspherecontaining tissues presented more intense staining for Safranin $\mathrm{O}$ and collagen type II. While -MS base material stained minimally for collagen type I, +MS constructs exhibited spotty collagen type I staining that appeared to be in and around the locations of partially degraded microspheres, which were not present in -MS tissues (Figure 2E). The amount of GAG normalized to DNA was more than double in +MS tissues $(92.3 \pm 15.4 \mathrm{GAG} / \mathrm{DNA}(\mu \mathrm{g} / \mu \mathrm{g}))$ compared to that in $-\mathrm{MS}$ tissues $(39.5 \pm 5.0 \mathrm{GAG} / \mathrm{DNA}(\mu \mathrm{g} / \mu \mathrm{g}))$ further supporting that $+\mathrm{MS}$ tissues were more chondrogenic.

ECM scaffolds were then fabricated from the tissue engineered cartilage base materials. Microsphere-containing sheets produced $50 \%$ more scaffolds than -MS sheets because more tissue (by wet weight) was produced in the $+\mathrm{MS}$ sheets. Specifically, a single -MS tissue engineered sheet produced 2.2 -MS scaffolds while $1+$ MS sheet produced $3.3+$ MS scaffolds. Cylindrically shaped dry scaffolds after DHT cross-linking were soft and spongy (Figure 2F). Hydrated EDC-NHS cross-linked scaffolds did not maintain their shape outside of aqueous solutions (Figure 2F, inset). Their microporous structure was evident from histological sections (Figure $2 \mathrm{G}-\mathrm{J}$ ). Both types of

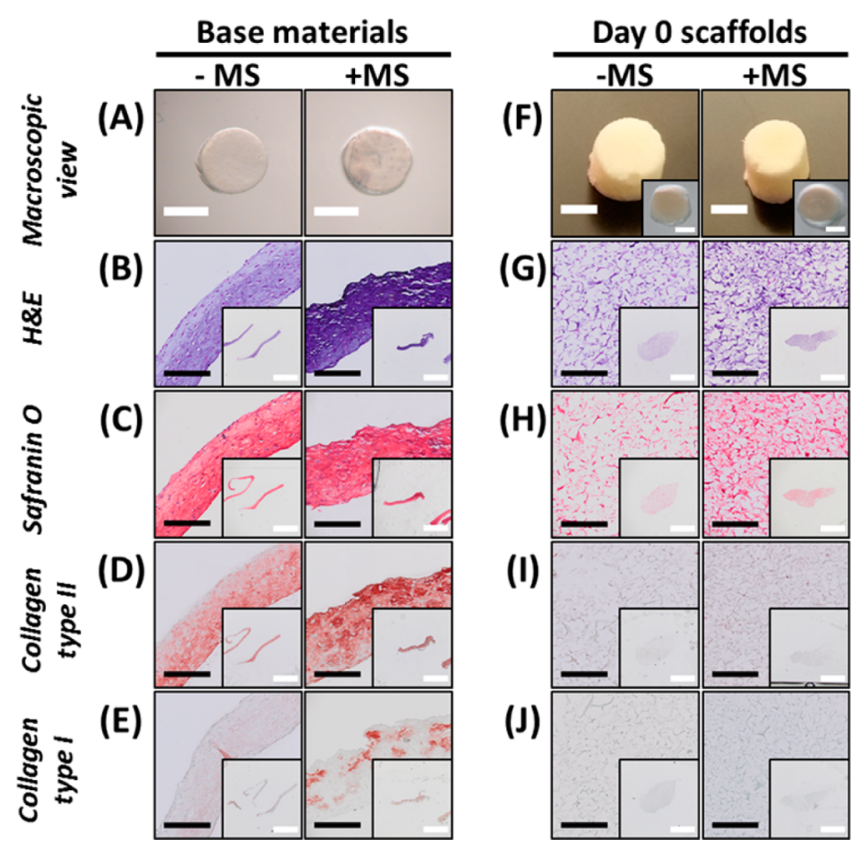

Figure 2. Macroscopic, histological, and immunohistochemical characterization of tissue engineered cartilage sheets cultured with TGF- $\beta 1$ in the media (-MS) or with TGF- $\beta 1$-loaded microspheres (+MS) used as the (A-E) base materials for scaffolds and (F-J) empty day 0 ECM scaffolds fabricated from these materials. (A) Macroscopic images of $3 \mathrm{~mm}$ diameter punches of base material sheets and $(\mathrm{F})$ individual day 0 scaffolds in dry form after DHT cross-linking (main image) and hydrated form after EDC-NHS cross-linking (inset). Tissue sections were stained with $(\mathrm{B}, \mathrm{G}) \mathrm{H} \& \mathrm{E},(\mathrm{C}, \mathrm{H})$ Safranin $\mathrm{O}$ for GAG (pink/red), (D,I) human collagen type II (red), and (E,J) human collagen type I (red) with a Fast Green counterstain. White scale bars are $2 \mathrm{~mm}$, and black scale bars are $200 \mu \mathrm{m}$.

porous scaffolds stained strongly for basophilic structures (Figure 2G) and GAG with greater staining intensity in the +MS scaffolds (Figure 2H). Neither scaffold stained for collagen type II (Figure 2I) or collagen type I (Figure 2J).

The scaffold fabrication process affected the quantified amounts of GAG and DNA in the scaffolds. The biochemical content of engineered tissue base material used to make 1 scaffold was compared to that of 1 scaffold on day 0, after EDCNHS cross-linking but before cell-seeding (Figure 3). The scaffold manufacture process significantly reduced the DNA (Figure 3A) and GAG (Figure 3B) contents of both -MS and +MS day 0 scaffolds compared to the base material. Scaffolds derived from + MS tissues contained significantly more GAG and similar amounts of DNA compared to scaffolds made from -MS tissues.

Characterization of Cell-Laden Scaffolds and Comparison to Scaffold-Free Controls. Scaffolds derived from both hMSC-only tissue engineered cartilage and microspherecontaining tissue engineered cartilage were reseeded with allogeneic hMSCs. Cell-laden scaffolds (derived from both + MS and -MS tissues) were either cultured in media supplemented with $10 \mathrm{ng} / \mathrm{mL}$ TGF- $\beta 1$ (exo scaffolds) or soak loaded with TGF- $\beta 1$ (loaded scaffolds) for delivery to the infiltrating hMSCs. All tissues became robust, pearly neocartilage that could be easily manipulated (Figure 4A). Cell infiltration and deposition of newly synthesized cartilaginous ECM were not uniform within all scaffolds. This was evident macroscopically as the ECM scaffold was visible on the edges of 

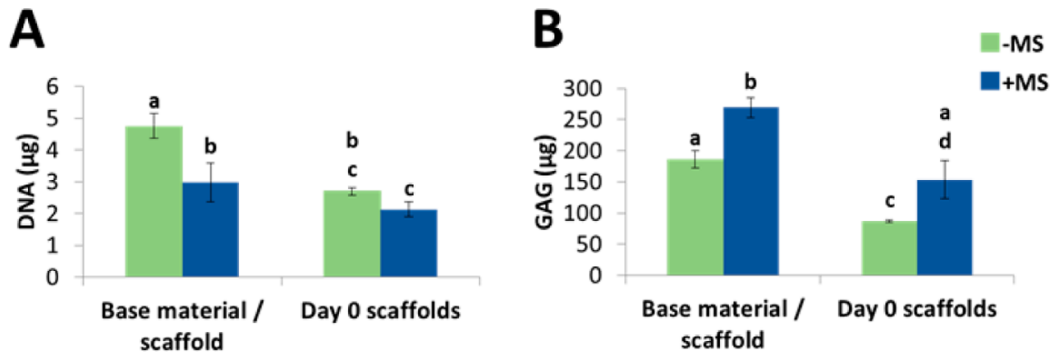

Figure 3. Biochemical characterization of base materials and day 0 scaffolds. (A) DNA and (B) GAG content of tissue engineered cartilage sheets cultured with TGF- $\beta 1$ in the media ( $-\mathrm{MS}$, green) or with TGF- $\beta$ 1-loaded microspheres (+MS, blue) used as the base materials for the fabrication of 1 scaffold and DNA and GAG content of empty day 0 ECM scaffolds fabricated from these materials. Groups that do not share a letter are statistically significant $(p<0.05)$.
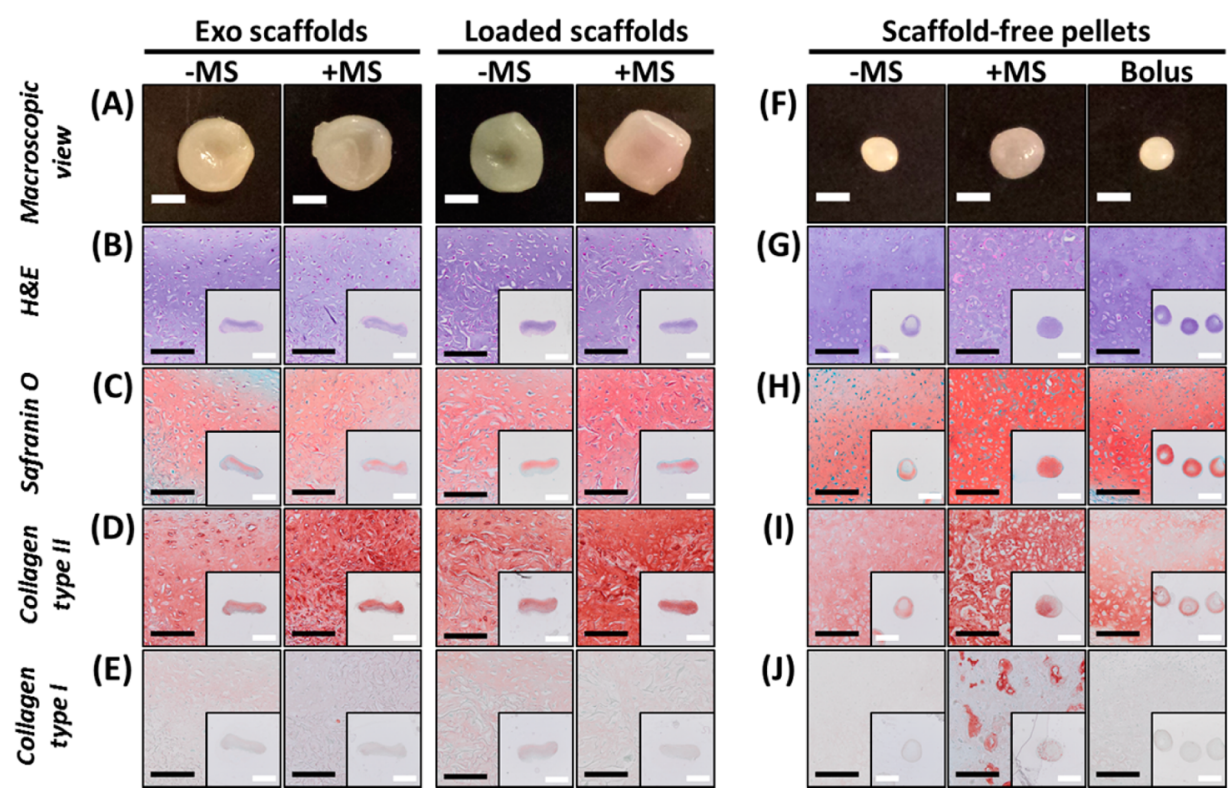

Figure 4. Macroscopic, histological, and immunohistochemical characterization of (A-E) ECM scaffolds seeded with hMSCs and (F-J) scaffoldfree hMSC pellets. Vertical sections taken through the thickness of the tissues were stained with (B,G) H\&E, (C,H) Safranin O for GAG (pink/red), $(\mathrm{D}, \mathrm{I})$ human collagen type II (red), and (E,J) human collagen type I (red) with a Fast Green counterstain. (A-E) Scaffolds were made from tissue engineered cartilage cultured with TGF- $\beta 1$ in the media $(-\mathrm{MS})$ or with TGF- $\beta 1$-loaded microspheres (+MS). hMSC-seeded scaffolds were cultured with media-supplemented TGF- $\beta 1$ (exo scaffolds) or with TGF- $\beta 1$ loaded into the scaffolds on day 0 (loaded scaffolds). (F-J) Pelleted scaffold-free hMSCs cultured with TGF- $\beta 1$ in the media (-MS), with TGF- $\beta 1$-loaded microspheres (+MS), or with a bolus of TGF- $\beta 1$ on day 0 (bolus) were used for comparison. White scale bars are $2 \mathrm{~mm}$, and black scale bars are $200 \mu \mathrm{m}$.

some constructs and in histological tissue sections in the vertical plane through the thickness of the tissues (Figure 4BD) and a randomly oriented, nonvertical plane (Figure S1AC). Nevertheless, all tissues were stained for Safranin O for GAG (Figures 4C and S1B) and collagen type II (Figures 4D and S1C) with limited collagen type I staining (Figures $4 \mathrm{E}$ and S1D). GAG and collagen type II staining intensity did not vary with growth factor presentation mechanism (exo scaffolds vs loaded scaffolds), but scaffolds derived from +MS sheets appeared to contain more collagen type II compared to that of the - MS scaffolds.

Quantification of GAG and DNA contents revealed that -MS scaffolds seeded with hMSCs produced cartilage with more GAG (Figure 5A, not significant for exo scaffolds) and GAG normalized to DNA (Figure 5C) compared to cell-seeded + MS scaffolds, with no differences in DNA content among the exo scaffolds but significantly more DNA in the -MS loaded scaffold compared to that of + MS loaded scaffold (Figure $5 \mathrm{~B}$ ). When TGF- $\beta 1$ was provided from -MS scaffolds (-MS, loaded scaffolds), GAG-rich matrix deposition was further enhanced compared to TGF- $\beta 1$ supplemented in the media for the same type of scaffold ( - MS, exo scaffolds) as reflected in a statistically significant increase in the total amount of GAG and GAG/DNA with no significant difference in the DNA content (Figure 5B). Presentation of TGF- $\beta 1$ from + MS scaffolds (+MS, loaded scaffolds) did not significantly alter the GAG content or GAG/DNA of constructs compared to that in media supplemented TGF- $\beta 1$ (+MS, exo scaffolds), although the + MS loaded scaffolds had significantly less DNA/construct. However, in all of the scaffolded tissues the measured amount of GAG (Figure 5A) and DNA (Figure 5B) may not represent exclusively newly formed cartilage tissue because empty day 0 scaffolds contained some DNA and GAG after scaffold manufacture (Figure 3). Dashed lines on each bar in the GAG and DNA graphs represent the DNA and GAG contents of day 0 empty scaffolds for reference. However, the histology suggests that much of the cartilage tissue in harvested exo and loaded scaffolds is due to the seeded cells and not the scaffold (Figure 4). 

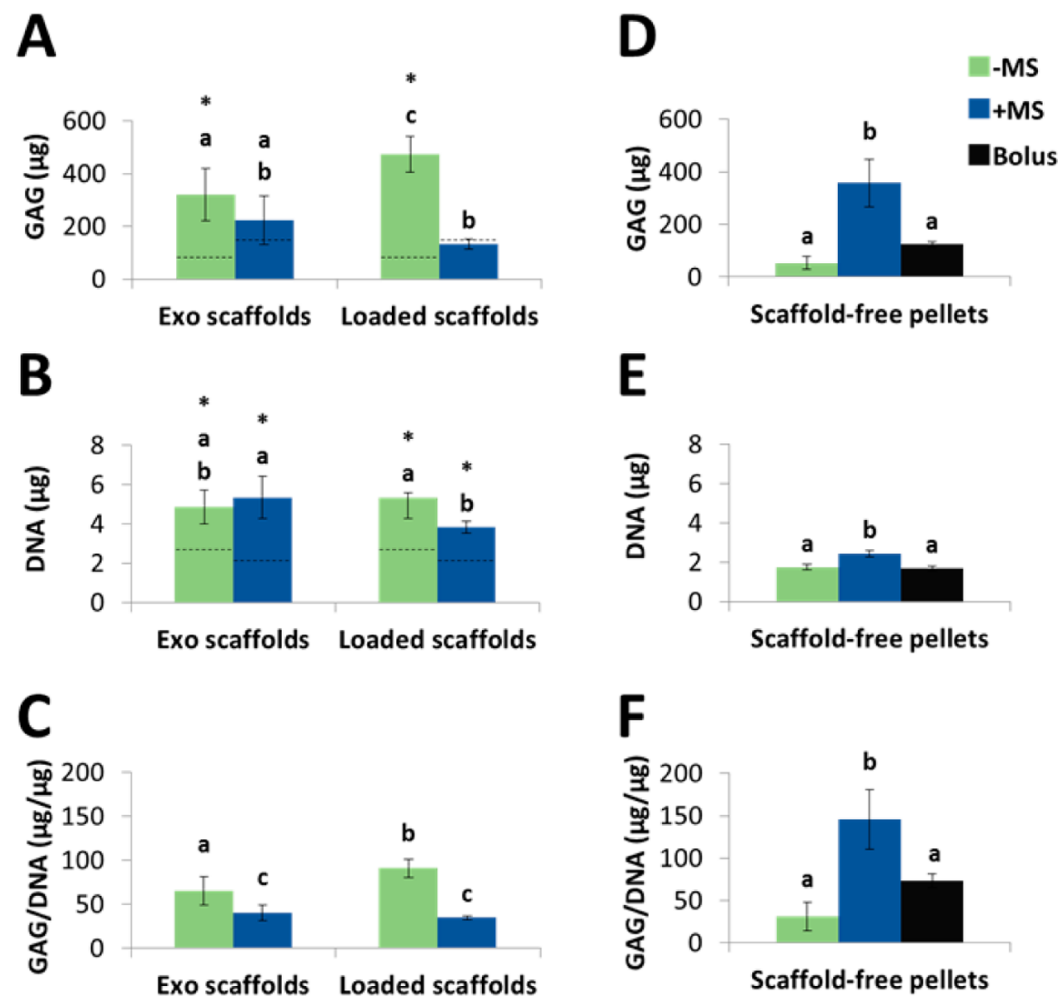

Figure 5. Biochemical characterization of exo scaffolds, loaded scaffolds, and scaffold-free pellets. (A,D) GAG, (B,E) DNA, and (C,F) GAG normalized to DNA content of (A-C) ECM scaffolds seeded with hMSCs and (D-F) scaffold-free hMSC pellets. Scaffolds were made from tissue engineered cartilage cultured with TGF- $\beta 1$ in the media (-MS, green) or with TGF- $\beta 1$-loaded microspheres (+MS, blue). (A-C) hMSCs-seeded scaffolds were cultured with media-supplemented TGF- $\beta 1$ (exo scaffolds) or with TGF- $\beta 1$ loaded into the scaffolds on day 0 (loaded scaffolds). (DF) Pelleted scaffold-free hMSCs cultured with TGF- $\beta 1$ in the media (-MS, green), with TGF- $\beta$ 1-loaded microspheres (+MS, blue), or with a bolus of TGF- $\beta 1$ on day 0 (bolus, gray) were used for comparison. Groups that do not share a letter are statistically significant $(p<0.05)$.
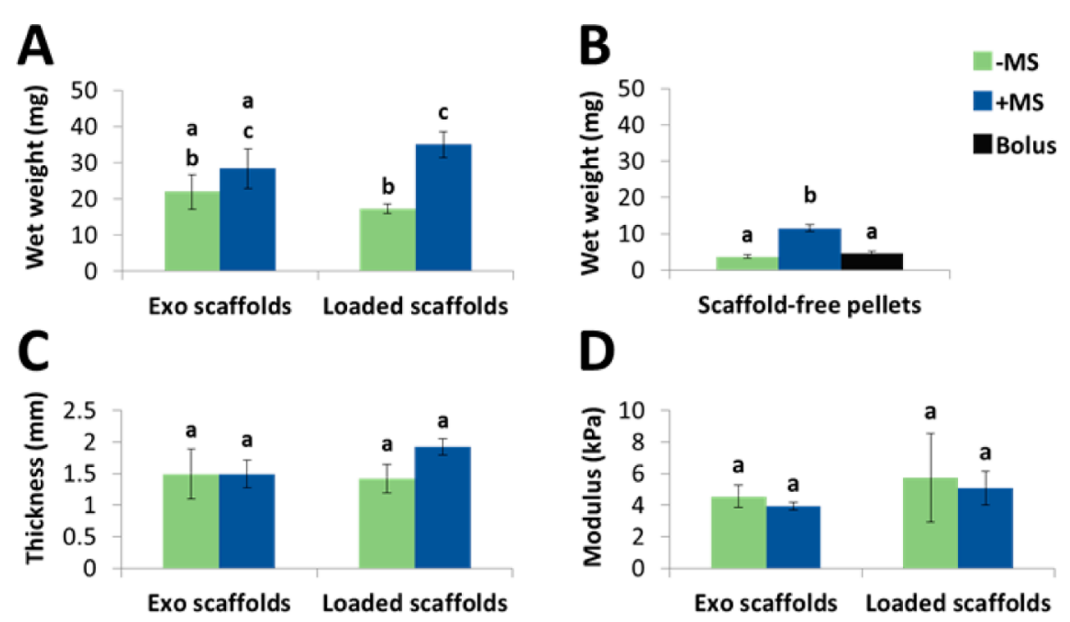

Figure 6. Wet weights of (A) ECM scaffolds seeded with hMSCs and (B) scaffold-free pellets, and (C) thickness and (D) equilibrium modulus of cell-laden ECM scaffolds. Scaffolds were made from tissue engineered cartilage cultured with TGF- $\beta 1$ in the media ( - MS, green) or with TGF- $\beta 1$ loaded microspheres (+MS, blue). (A,C,D) hMSC-seeded scaffolds were cultured with media-supplemented TGF- $\beta 1$ (exo scaffolds) or with TGF- $\beta 1$ loaded into the scaffolds on day 0 (loaded scaffolds). (B) The wet weights of pelleted scaffold-free hMSCs cultured with TGF- $\beta 1$ in the media (-MS, green), with TGF- $\beta 1$-loaded microspheres (+MS, blue) or with a bolus of TGF- $\beta 1$ on day 0 (bolus, gray) were used for comparison to (A) wet weights of scaffolded tissues. Groups that do not share a letter are statistically significant $(p<0.05)$.

The role of the scaffold on cartilage tissue formation was investigated by comparing cell-laden scaffolds to scaffold-free pellets composed of the same number of hMSCs from the same donor and passage as those seeded on the scaffolds, which received $10 \mathrm{ng} / \mathrm{mL}$ TGF- $\beta 1$ in the media (-MS), $150 \mathrm{ng}$ of TGF- $\beta 1$ soak loaded into microspheres (+MS), or $150 \mathrm{ng}$ of bolus TGF- $\beta 1$ treatment on day 0 (bolus) (Figure $4 \mathrm{~F}-\mathrm{J}$ ). It may be worth noting that while for the first $2 \mathrm{~h}$ of culture, the bolus scaffold-free pellets and the loaded scaffolds were exposed to the same TGF- $\beta 1$ concentration $(3.75 \mu \mathrm{g} / \mathrm{mL})$, for hours $2-$ 24 after cell seeding the bolus group was subject to a higher concentration of TGF- $\beta 1(750 \mathrm{ng} / \mathrm{mL})$ compared to that of the loaded scaffolds (60 ng/mL TGF- $\beta 1$ ). This was because scaffold-free pellets, which were formed in 96-well plates, could 
not be transferred into the $5 \mathrm{~mm}$ agarose wells in 12-well plates, which accept more media volume, until $24 \mathrm{~h}$ after formation. After day 1 , the TGF- $\beta 1$ regimen was matched for the bolus scaffold-free pellets and loaded scaffolds groups. Macroscopically, the tissues without scaffolds were much smaller and took on a spherical conformation (Figure 4F) compared to cellladen scaffolds, which were larger and puck-shaped (Figure 4A). Histologically, cartilaginous areas within scaffold-free pellets stained similarly or more intensely for GAG (Figure $4 \mathrm{H})$ compared to scaffolded tissues (Figure 4C). Conversely, type II collagen staining in scaffold-based constructs (Figure 4D) was stronger compared to that in -MS and bolus scaffoldfree groups but similar to the scaffold-free aggregates with microspheres (Figure 4I). Just as before, minimal collagen type I staining was evident in all tissues except for positive staining of gelatin microspheres which had not fully degraded (Figure $4 \mathrm{~J})$. Among the scaffold-free constructs, $+\mathrm{MS}$ pellets stained the strongest for Safranin O and type II collagen, followed by bolus pellets, and then -MS pellets, which showed the least amount of staining. Scaffold-free pellets without microspheres (-MS and bolus) had heterogeneous ECM deposition with markedly more cartilage on the periphery than the interior (Figure 4GI).

DNA and GAG contents of scaffold-free pellets were also measured. Scaffold-free controls without microspheres (-MS and bolus) had similar or less measured GAG compared to that of scaffold-based tissues (Figure 5A,D). Conversely, +MS scaffold-free pellets had more GAG than cell-laden + MS scaffolds but similar or less GAG compared to cell-laden -MS scaffolds (Figure 5A,D). The amount of DNA in scaffold-free pellets was less than that of scaffolded tissues even though the same number of cells was used for engineering the constructs (Figure 5B,E), and this may be due to the residual DNA present from the day 0 scaffolds. Surprisingly, bolus treatment with $150 \mathrm{ng}$ of TGF- $\beta 1$ on only day 0 resulted in higher, but not significantly, GAG and GAG/DNA than continuous supplementation in the scaffold-free -MS group (Figure $5 \mathrm{~F}$ ). Incorporation of TGF- $\beta$ 1-loaded microspheres generated significantly more GAG and GAG/DNA compared to that in all other scaffold-free groups (Figure 5E,F).

Cartilage made using engineered ECM scaffolds was sizable compared to that in scaffold-free controls. Scaffolded constructs (Figure 6A) were much heavier than the scaffold-free pellets (Figure 6B) with $+\mathrm{MS}$ scaffolds resulting in more wet weight than - MS scaffolds (Figure 6A, significant in loaded scaffolds). Among scaffold-free pellets, + MS aggregates were significantly heavier (Figure 6B). These findings support the macroscopic observations that engineered cartilage made using scaffolds was much larger than cartilage made without scaffolds (Figure 4). In addition, while not significant, cell-seeded + MS scaffolds loaded with TGF- $\beta 1$ produced cartilage that was thicker than that of the other cell-laden scaffolds (Figure 6C) and had greater average surface area (Figure S2). Mechanical testing of tissue engineered scaffold-based cartilage revealed no significant differences in equilibrium modulus among the groups (Figure 6D).

\section{DISCUSSION}

While cartilage regeneration has been challenging, ${ }^{36,37}$ ECMbased materials for cartilage regeneration have shown promising results. ${ }^{28-30,38-42}$ In particular, in vitro stem cellderived matrices may be more clinically applicable because they do not rely on mature cartilage as the base material, avoiding supply limitations, immune complications when used in an autologous manner, and donor site morbidity and pain associated with autologous therapies. In addition, the ECM from tissues produced by chondrogenically differentiating stem cells in vitro may promote chondrogenesis of reseeded stem cells more than matrices derived from in vitro-cultured mature chondrocytes. $^{39}$ The chondrogenic potential of MSCs has been long shown. ${ }^{43,44}$ In our laboratory, incorporation of chondrogenic TGF- $\beta 1$-releasing gelatin microspheres into high-density hMSC cultures has led to improved cartilage tissue formation compared to that in cultures supplemented with TGF- $\beta 1$ in the media. ${ }^{22,24,27}$ In this work, the chondrogenic potential of the ECM derived from hMSC tissues engineered with TGF- $\beta 1$ microspheres compared to ECM from hMSC tissues cultured in standard media supplemented with TGF- $\beta 1$ was investigated (Figure 1). Additionally, the ability of a TGF- $\beta 1$-loaded cellderived ECM scaffold to drive chondrogenesis of reseeded hMSCs was explored.

As expected and similar to previously published results, ${ }^{22}$ cell sheets composed of hMSCs with TGF- $\beta 1$-loaded microspheres produced tissue that was more cartilaginous than hMSCs with TGF- $\beta 1$ in the media. Although microspheres prepared by this protocol fully degraded in sheet culture by 3 weeks in a previous report ("low $\mathrm{Gp}^{\text {"22 }}$ ), in this study even after 4 weeks of culture, some remnant gelatin microspheres were still present within the sheets. Differences in batches of gelatin and the cross-linker genipin, and cell-secreted enzymes, which likely vary from hMSC donor to donor, may be responsible for prolonging the presence of the gelatin. ${ }^{45}$

Novel ECM scaffolds were successfully fabricated from scaffold-free hMSC-derived tissue engineered cartilage. Morphologically, they resembled scaffolds fabricated in this manner from native porcine tissue. ${ }^{18}$ However, scaffolds derived from engineered tissues contained less DNA (4.1× less in -MS and $5.2 \times$ less in $+\mathrm{MS}$ scaffolds; Figure $3 \mathrm{~A}$ ) compared to that in scaffolds made from native porcine tissues using the same protocol. Less nucleic material in scaffolds fabricated from engineered cartilage-derived ECM scaffolds described in this work may be beneficial in reducing their immunogenicity in an allogeneic therapy. ${ }^{14}$ Compared to the engineered cartilage base material, the scaffold fabrication process reduced DNA content by $43 \%$ in the - MS group and by $29 \%$ in the + MS group (Figure 3). Genetic matter within scaffolds may be further reduced in the future with DNase/RNase treatment. ${ }^{46}$ Nevertheless, many groups have observed limited immunogenic response with allogeneic cartilage regeneration therapies, ${ }^{47}$ so additional processing may not be required.

Most decellularization/devitalization techniques for the production of ECM-derived materials aim to maintain as much of the original ECM composition as possible, but some loss of ECM components is unavoidable. ${ }^{11,13,14}$ Our scaffold fabrication process (i.e., freeze/thaw, homogenization, controlled freeze-drying, DHT, and EDC-NHS cross-linking) allowed for the retention of $47 \%$ and $57 \%$ of the original amount of GAG for $-\mathrm{MS}$ and $+\mathrm{MS}$ tissues, respectively (Figure 3B), which is similar to or greater than other ECM preparation methods from engineered cartilage. ${ }^{48,49}$ While intra-articular injections of glucosamine, a building block of GAG, have shown promising findings in animal models of osteoarthritis, ${ }^{50}$ some in vitro evaluations are not as positive. Presence of glucosamine during initial cell seeding significantly inhibited chondrocyte attachment to tissue culture plastic ${ }^{51}$ and hMSC self-assembly into pellets in chondrogenic medium. ${ }^{52} \mathrm{~A}$ high concentration of 
glucosamine also inhibited chondrogenic matrix accumulation. $^{51,52}$ Therefore, high GAG retention in ECM scaffolds may not be critical for chondroconduction of reseeded cells. While approximately half of the GAG was retained in the scaffolds, collagen type II staining was reduced during scaffold fabrication (Figure 2D,I), likely as result of protein denaturation during DHT cross-linking of the scaffolds. The influence of collagen type II on new cartilage formation is also still unclear. While some studies have shown that the presence of collagen type II in day 0 matrices supports seeded MSC chondrogenesis, ${ }^{53,54}$ others present contradicting findings. ${ }^{28,54}$ For example, compared to less mature (1-week-old) cartilaginous ECM scaffolds, more mature (3-week-old) hMSC-derived cartilaginous ECM scaffolds containing more type II collagen and aggrecan, cartilage-specific proteoglycan core protein, were not as chondrogenic for reseeded hMSCs. ${ }^{28}$

Our findings support the idea that ECM scaffolds with lower GAG content may promote newly synthesized GAG deposition by reseeded hMSCs to a greater extent compared to ECM scaffolds with higher GAG content. hMSCs with localized TGF- $\beta 1$ released via gelatin microspheres (+MS) produced scaffolds with decreased GAG and GAG/DNA (Figure 5A,C) compared to that of scaffolds made from less cartilaginous tissue (-MS). Microsphere-incorporated tissues may still be an attractive material for ECM scaffolds because, first, they showed stronger staining for type II collagen (Figure 4D), which gives cartilage its tensile strength. ${ }^{55}$ Second, $50 \%$ more scaffolds were made with + MS tissues due to increased matrix production in the engineered cartilage base material. In this work, 4-week-old sheets were the base materials, but it may be possible to use + MS engineered cartilage at an earlier time point to gain the potential advantage of having less $\mathrm{GAG}^{27}$ while still benefiting from enhanced matrix production compared to that of $-\mathrm{MS}$ tissues. At the same time, scaffolds made by ECMs of chondrogenically induced hMSCs have been previously shown to be more chondroinductive than ECMs of undifferentiated hMSCs, ${ }^{30}$ suggesting that some neocartilaginous ECM components of the base material may be desirable for development of cartilage tissues by the reseeded cells.

Newly synthesized cartilage matrix within the ECM scaffolds was not homogeneous, but it may be possible to ameliorate this by improving hMSC infiltration into the ECM scaffolds. In this work, hMSCs did not exhibit uniform migration and/or survival and subsequent matrix deposition in the ECM scaffolds (Figures $4 \mathrm{~B}-\mathrm{D}$ and $\mathrm{S} 1 \mathrm{~A}-\mathrm{C}$ ). In contrast, when infrapatellar fat pad-derived stem cells were seeded into ECM scaffolds fabricated by the same protocol, cellular infiltration and matrix deposition were more uniform. ${ }^{18}$ hMSC seeding and new matrix deposition may be improved by altering scaffold pore structure $^{56}$ and pore size or porosity, ${ }^{18,57}$ scaffold mechanical properties, $^{58}$ and/or degradation profile ${ }^{59}$ by changing the concentration of the ECM slurry, the size of the ECM particles, or scaffold cross-linking protocols, or by changing the culture conditions, such as seeding cells into dry scaffolds or using a perfusion bioreactor. ${ }^{60}$

Importantly, engineered cartilage-derived ECM scaffolds soak loaded with TGF- $\beta 1$ induced chondrogenesis of seeded hMSCs at least as well as ECM scaffolds that were cultured in TGF- $\beta 1$-supplemented media. This is expected because some ECM molecules can modulate growth factor presentation and availability. ${ }^{61,62}$ It is possible that cartilage tissue formation was additionally influenced by the high initial concentrations of TGF- $\beta 1$ for $2 \mathrm{~h}(3.75 \mu \mathrm{g} / \mathrm{mL}$; $375 \times$ greater than exo scaffolds $)$ followed by $60 \mathrm{ng} / \mathrm{mL}$ ( $6 \times$ greater than exo scaffolds) until day 3 of culture. Nevertheless, the amount of TGF- $\beta 1$ soak loaded into each scaffold (150 ng) was less than the total amount of TGF- $\beta 1$ to which seeded cells were exposed in the exo scaffolds groups ( $200 \mathrm{ng}$ of TGF- $\beta 1=8$ media changes (including day 0 media) $\times 2.5 \mathrm{~mL}$ of media $\times 10 \mathrm{ng}$ of TGF- $\beta 1 / \mathrm{mL}$ media) . These results support our previous findings that showed that native cartilage-derived ECM scaffolds soak loaded with TGF$\beta 3$ can successfully induce chondrogenesis of infrapatellar fat pad-derived stem cells at least as well as media-supplemented scaffolds. ${ }^{17,18}$ In addition, in a different a system, particles of decellularized tissue-engineered cartilage ECM incorporated within hMSC aggregates do not induce chondrogenesis without TGF- $\beta 1$ supplementation (unpublished data), so TGF- $\beta 1$ delivery from the scaffolds formed using this material may be critical to generating cartilaginous tissue without exogenous growth factor supplementation in the culture media. The chondrogenesis inducing TGF- $\beta 1$-loaded ECM scaffolds make in vitro culture potentially less labor intensive and expensive by removing the need for growth factor supplementation at each media change. TGF- $\beta 1$-loaded scaffolds may also exhibit enhanced in vivo performance because they may be able to continue to stimulate seeded cells even after implantation.

Our tissue engineered ECM scaffold approach has specific advantages over scaffold-free constructs. While the matrix of scaffold-free constructs was at least as cartilaginous, based on Safranin $\mathrm{O}$ and collagen type II staining (Figure 4) as well as quantified GAG/DNA (Figure 5C,F), there were a few key differences. The use of scaffolds allowed for a better cartilage matrix distribution within constructs compared to -MS and bolus scaffold-free pellets, which had a noncartilaginous core. As mentioned previously, cell seeding within the scaffolds could be improved to produce even more uniform cartilage matrix distribution. While the use of TGF- $\beta 1$-microspheres in scaffoldfree pellets avoided the poor matrix distribution, all scaffold-free pellets made tissue that was markedly smaller (Figure 4A,F) and lighter (Figure 6A,B) than scaffold-based constructs, which were made from the same number of hMSCs. In symptomatic knees, the majority $(61 \%)$ of cartilage lesions are greater than $0.5 \mathrm{~cm}^{2}{ }^{63}$ Thus, it is more clinically relevant to engineer larger constructs. Nevertheless, the cross-sectional areas of the cellladen scaffolds described here were less than $0.5 \mathrm{~cm}^{2}$, with average values ranging from $0.14-0.18 \mathrm{~cm}^{2}$ and no significant differences between the groups (Figure S2). However, larger ECM scaffolds can easily be fabricated by increasing the size of the molds to hold more ECM slurry. Another advantage of the ECM-based scaffold approach over the scaffold-free pellets is its potential to be used as an off-the-shelf product. ECM scaffolds may be fabricated from prescreened chondrogenic and immune-matched hMSC donors for use as an allogeneic therapy, or patients' own hMSCs can be harvested and used to fabricate ECM scaffolds for immediate or future autologous use.

Comparison of the scaffold-based approach to the scaffoldfree approach for cartilage tissue engineering also led to notable findings about the implications of TGF- $\beta 1$-supplementation regimen on chondrogenesis within scaffold-free pellets. To mimic the treatment of exo and loaded scaffold-based constructs, scaffold-free pellets were similarly cultured with exogenously supplemented TGF- $\beta 1$ in the media (-MS) or with $150 \mathrm{ng}$ TGF- $\beta 1$ supplied on day 0 (bolus). The bolus TGF- $\beta 1$ treatment supplied less TGF- $\beta 1$ than the amount -MS hMSCs pellets were exposed to during the culture period, but it led to similar chondrogenesis (Figures 4 and 5). This 
sheds light on the importance of timing and concentration of TGF- $\beta 1$ supplementation. Induction of chondrogenesis in hMSC cultures is typically achieved via continuous $10 \mathrm{ng} / \mathrm{mL}$ TGF- $\beta 1$ media supplementation, ${ }^{64}$ but our findings support a recent report that short-term treatment with a high dose of TGF- $\beta$ during in vitro culture increased the total amount of elaborated chondrogenic matrix. ${ }^{65}$ In fact, developmentally, TGF- $\beta 1$ signaling is limited to early stages of hMSC aggregation and condensation during chondrogenesis, and it does not seem to play a critical role once hMSCs are differentiated. ${ }^{66}$ Specifically, Kim et al. found that high TGF- $\beta 3$ dosage $\left(100 \mathrm{ng} / \mathrm{mL}\right.$ TGF- $\beta 3$ or $60 \mathrm{ng}$ of TGF- $\beta 3 / 10^{6}$ MSCs) supplied 2 times over the course of 1 week resulted in significantly improved mechanical properties and nearly doubled GAG/WW after 9 weeks of culture compared to continuous supplementation with $10 \mathrm{ng} / \mathrm{mL}$ TGF- $\beta 3 .^{65}$ In the work presented here, bolus scaffold-free pellets had approximately double the GAG and GAG/DNA (Figure 5D, F; not significant) and nearly double the GAG/WW $(14.15 \pm 5.74$ vs $26.91 \pm 2.13 \mathrm{GAG} / \mathrm{WW}(\mu \mathrm{g} / \mathrm{mg}), p<0.05)$ compared to those of the $-\mathrm{MS}$ scaffold-free pellets. In detail, the bolus group was treated with a single dose of TGF- $\beta 1(2 \mathrm{~h}$ at $3.75 \mu \mathrm{g} / \mathrm{mL}$ $\left(150 \mathrm{ng} / 0.5 \times 10^{6} \mathrm{hMSCs}\right)$ followed by a dilution to $750 \mathrm{ng} /$ $\mathrm{mL}\left(30 \mathrm{ng} / 0.5 \times 10^{6} \mathrm{hMSCs}\right)$ for $22 \mathrm{~h}$ and a further dilution to $60 \mathrm{ng} / \mathrm{mL}\left(2.4 \mathrm{ng} / 0.5 \times 10^{6} \mathrm{hMSCs}\right)$ until the first media change at day 3$)$, while the -MS group was supplemented continuously with $10 \mathrm{ng} / \mathrm{mL}$ TGF- $\beta 1\left(0.4 \mathrm{ng} / 0.5 \times 10^{6}\right.$ hMSCs for $2 \mathrm{~h}, 2 \mathrm{ng} / 0.5 \times 10^{6} \mathrm{hMSCs}$ for $22 \mathrm{~h}$ and $25 \mathrm{ng} /$ $0.5 \times 10^{6} \mathrm{hMSCs}$ for the rest of the culture period). Although the concentration of TGF- $\beta 1$ in the bolus group medium is $0.6 \times$ of that used by Kim et al. for days 2 and 3 of culture, it is much higher during the first $24 \mathrm{~h}(37.5 \times$ greater for the first $2 \mathrm{~h}$ and then $7.5 \times$ greater for the next $22 \mathrm{~h}$ ). Therefore, additional studies are necessary to determine the most effective TGF- $\beta 1$ supplementation regimen to minimize cost while maximizing chondrogenesis. Still, when gelatin microspheres (+MS scaffold-free pellets) were used to deliver the same $150 \mathrm{ng}$ of TGF- $\beta 1$ as was added to the bolus group on day 0 from within the scaffold-free pellets, chondrogenesis was significantly enhanced compared to that of the -MS and bolus pellets (Figures 4 and 5) supporting our previous findings on the benefits of this approach. ${ }^{22,24,26,27}$ Additionally, while a bolus TGF- $\beta 1$ treatment resulted in promising in vitro findings, controlled release of TGF- $\beta 1$ may be more beneficial in vivo ${ }^{64}$ because this approach may allow for implantation of patients' cells combined with the off-the-shelf, growth factor-loaded constructs with minimal preculture.

\section{CONCLUSION}

In this work, a novel hMSC-derived engineered cartilage tissue was used to fabricate chondrogenic ECM-based scaffolds. Scaffolds fabricated out of less cartilaginous engineered tissue resulting from hMSCs cultured in TGF- $\beta 1$-supplemented media resulted in more GAG-rich matrix elaboration by reseeded hMSCs compared to that of scaffolds made from more cartilage-like base material, which was derived from tissue developed by hMSCs with TGF- $\beta 1$-releasing gelatin microspheres. However, 50\% more scaffolds were fabricated from the latter material making it a potentially worthwhile tissue with which to move forward. Additionally, TGF- $\beta$ 1-loaded ECM scaffolds successfully induced chondrogenesis of reseeded hMSCs similarly or better than media-supplemented groups with less total growth factor, further establishing the benefits of this approach. Scaffolded constructs created cartilage that was much larger than scaffold-free controls, making them more clinically relevant. Taken all together, this work demonstrates that scaffolds composed of ECMs of high-density stem cell engineered cartilage are a viable option for supporting chondrogenesis of seeded and infiltrating cells and have the potential to serve as an off-the-shelf auto- or allogeneic cartilage replacement therapy.

\section{ASSOCIATED CONTENT}

\section{Supporting Information}

The Supporting Information is available free of charge on the ACS Publications website at DOI: 10.1021/acsbiomaterials.6b00654.

Photomicrographs of histological and immunohistochemical staining of ECM scaffolds seeded with hMSCs sectioned in a randomly oriented, nonvertical plane and cross-sectional areas of ECM scaffolds seeded with hMSCs (PDF)

\section{AUTHOR INFORMATION}

\section{Corresponding Author}

*Tel: 1-216-368-6425. E-mail: eben.alsberg@case.edu. ORCID $\odot$

Eben Alsberg: 0000-0002-3487-4625

\section{Present Address}

OH.V.A.: Center for Neuroscience and Cell Biology, University of Coimbra, Coimbra, Portugal.

\section{Notes}

The authors declare no competing financial interest.

\section{ACKNOWLEDGMENTS}

We thank Amad Awadallah for sectioning harvested tissues and conducting Safranin $\mathrm{O}$ and H\&E staining. Christina Cheng, Alexandra McMillan, and Bradley Lai are also gratefully acknowledged for their contributions to initial experiments on decellularized tissues. We also gratefully acknowledge financial support from the National Institutes of Health (R01AR063194, R01AR069564, and R01AR066193 (to E.A.) and T32AR007505 (to A.D.D.)), European Research Council Starter Grant (StemRepair - Project number: 258463; to D.J.K.), Programme for Research in Third-Level Institutions Graduate Research Education Programme in Engineering (to H.V.A.), European Regional Development Fund (to H.V.A.), and the Higher Education Authority (to H.V.A.).

\section{REFERENCES}

(1) Gardner, O. F.; Archer, C. W.; Alini, M.; Stoddart, M. J. Chondrogenesis of mesenchymal stem cells for cartilage tissue engineering. Histol. Histopathol. 2013, 28 (1), 23-42.

(2) Flanigan, D. C.; Harris, J. D.; Trinh, T. Q.; Siston, R. A.; Brophy, R. H. Prevalence of chondral defects in athletes' knees: a systematic review. Med. Sci. Sports Exercise 2010, 42 (10), 1795-801.

(3) Lee, C. R.; Grodzinsky, A. J.; Hsu, H. P.; Martin, S. D.; Spector, $M$. Effects of harvest and selected cartilage repair procedures on the physical and biochemical properties of articular cartilage in the canine knee. J. Orthop. Res. 2000, 18 (5), 790-9.

(4) Cross, M.; Smith, E.; Hoy, D.; Nolte, S.; Ackerman, I.; Fransen, M.; Bridgett, L.; Williams, S.; Guillemin, F.; Hill, C. L.; Laslett, L. L.; Jones, G.; Cicuttini, F.; Osborne, R.; Vos, T.; Buchbinder, R.; Woolf, A.; March, L. The global burden of hip and knee osteoarthritis: estimates from the global burden of disease 2010 study. Ann. Rheum. Dis. 2014, 73 (7), 1323-30. 
(5) Lawrence, R. C.; Felson, D. T.; Helmick, C. G.; Arnold, L. M.; Choi, H.; Deyo, R. A.; Gabriel, S.; Hirsch, R.; Hochberg, M. C.; Hunder, G. G.; Jordan, J. M.; Katz, J. N.; Kremers, H. M.; Wolfe, F. National Arthritis Data, W., Estimates of the prevalence of arthritis and other rheumatic conditions in the United States. Part II. Arthritis Rheum. 2008, 58 (1), 26-35.

(6) Hootman, J. M.; Helmick, C. G. Projections of US prevalence of arthritis and associated activity limitations. Arthritis Rheum. 2006, 54 (1), 226-9.

(7) Gainer, K. Regenerative Medicines: Bone and Joint Applications; PHM032D; BCC Research: Wellesley, MA, 2015.

(8) Scotti, C.; Gobbi, A.; Karnatzikos, G.; Martin, I.; Shimomura, K.; Lane, J. G.; Peretti, G. M.; Nakamura, N. Cartilage repair in the inflamed joint: considerations for biological augmentation toward tissue regeneration. Tissue Eng., Part B 2016, 22 (2), 1-12.

(9) McGregor, A. J.; Amsden, B. G.; Waldman, S. D. Chondrocyte repopulation of the zone of death induced by osteochondral harvest. Osteoarthritis Cartilage 2011, 19 (2), 242-8.

(10) Roberts, S.; Menage, J.; Sandell, L. J.; Evans, E. H.; Richardson, J. B. Immunohistochemical study of collagen types I and II and procollagen IIA in human cartilage repair tissue following autologous chondrocyte implantation. Knee 2009, 16 (5), 398-404.

(11) Sutherland, A. J.; Converse, G. L.; Hopkins, R. A.; Detamore, M. $\mathrm{S}$. The bioactivity of cartilage extracellular matrix in articular cartilage regeneration. Adv. Healthcare Mater. 2015, 4 (1), 29-39.

(12) Benders, K. E.; van Weeren, P. R.; Badylak, S. F.; Saris, D. B.; Dhert, W. J.; Malda, J. Extracellular matrix scaffolds for cartilage and bone regeneration. Trends Biotechnol. 2013, 31 (3), 169-76.

(13) Cheng, C. W.; Solorio, L. D.; Alsberg, E. Decellularized tissue and cell-derived extracellular matrices as scaffolds for orthopaedic tissue engineering. Biotechnol. Adv. 2014, 32 (2), 462-84.

(14) Badylak, S. F.; Freytes, D. O.; Gilbert, T. W. Extracellular matrix as a biological scaffold material: Structure and function. Acta Biomater. 2009, 5 (1), 1-13.

(15) Reilly, G. C.; Engler, A. J. Intrinsic extracellular matrix properties regulate stem cell differentiation. J. Biomech. 2010, 43 (1), $55-62$.

(16) Cheng, N. C.; Estes, B. T.; Young, T. H.; Guilak, F. Genipincrosslinked cartilage-derived matrix as a scaffold for human adiposederived stem cell chondrogenesis. Tissue Eng., Part A 2013, 19 (3-4), 484-96.

(17) Almeida, H. V.; Liu, Y.; Cunniffe, G. M.; Mulhall, K. J.; Matsiko, A.; Buckley, C. T.; O’Brien, F. J.; Kelly, D. J. Controlled release of transforming growth factor-beta3 from cartilage-extra-cellular-matrixderived scaffolds to promote chondrogenesis of human-joint-tissuederived stem cells. Acta Biomater. 2014, 10 (10), 4400-9.

(18) Almeida, H. V.; Cunniffe, G. M.; Vinardell, T.; Buckley, C. T.; O’Brien, F. J.; Kelly, D. J. Coupling freshly isolated CD44(+) infrapatellar fat pad-derived stromal cells with a TGF-beta3 eluting cartilage ECM-derived scaffold as a single-stage strategy for promoting chondrogenesis. Adv. Healthcare Mater. 2015, 4 (7), 1043-53.

(19) Fitzpatrick, L. E.; McDevitt, T. C. Cell-derived matrices for tissue engineering and regenerative medicine applications. Biomater. Sci. 2015, 3 (1), 12-24.

(20) Lohan, P.; Coleman, C. M.; Murphy, J. M.; Griffin, M. D.; Ritter, T.; Ryan, A. E. Changes in immunological profile of allogeneic mesenchymal stem cells after differentiation: should we be concerned? Stem Cell Res. Ther. 2014, 5 (4), 99.

(21) Solorio, L. D.; Fu, A. S.; Hernandez-Irizarry, R; Alsberg, E. Chondrogenic differentiation of human mesenchymal stem cell aggregates via controlled release of TGF-betal from incorporated polymer microspheres. J. Biomed Mater. Res. A 2010, 92 (3), 1139-44.

(22) Solorio, L. D.; Vieregge, E. L.; Dhami, C. D.; Dang, P. N.; Alsberg, E. Engineered cartilage via self-assembled hMSC sheets with incorporated biodegradable gelatin microspheres releasing transforming growth factor-beta1. J. Controlled Release 2012, 158 (2), 224-32.

(23) Solorio, L. D.; Phillips, L. M.; McMillan, A.; Cheng, C. W.; Dang, P. N.; Samorezov, J. E.; Yu, X.; Murphy, W. L.; Alsberg, E.
Spatially organized differentiation of mesenchymal stem cells within biphasic microparticle-incorporated high cell density osteochondral tissues. Adv. Healthcare Mater. 2015, 4 (15), 2306-13.

(24) Dikina, A. D.; Strobel, H. A.; Lai, B. P.; Rolle, M. W.; Alsberg, E. Engineered cartilaginous tubes for tracheal tissue replacement via selfassembly and fusion of human mesenchymal stem cell constructs. Biomaterials 2015, 52, 452-62.

(25) Dikina, A. D.; Alt, D. S.; McMillan, A.; Herberg, S.; Strobel, H. A.; Zhang, Z.; Cao, M.; Lai, B. P.; Jeon, O.; Petsinger, V. I.; Rolle, M. W.; Alsberg, E. A modular strategy to engineer complex tissues, unpublished work.

(26) Dang, P. N.; Solorio, L. D.; Alsberg, E. Driving cartilage formation in high-density human adipose-derived stem cell aggregate and sheet constructs without exogenous growth factor delivery. Tissue Eng., Part A 2014, 20 (23-24), 3163-75.

(27) Solorio, L. D.; Dhami, C. D.; Dang, P. N.; Vieregge, E. L.; Alsberg, E. Spatiotemporal regulation of chondrogenic differentiation with controlled delivery of transforming growth factor-betal from gelatin microspheres in mesenchymal stem cell aggregates. Stem Cells Transl. Med. 2012, 1 (8), 632-9.

(28) Cai, R.; Nakamoto, T.; Kawazoe, N.; Chen, G. Influence of stepwise chondrogenesis-mimicking 3D extracellular matrix on chondrogenic differentiation of mesenchymal stem cells. Biomaterials 2015, 52, 199-207.

(29) Ravindran, S.; Kotecha, M.; Huang, C. C.; Ye, A.; Pothirajan, P.; Yin, Z.; Magin, R.; George, A. Biological and MRI characterization of biomimetic ECM scaffolds for cartilage tissue regeneration. Biomaterials 2015, 71, 58-70.

(30) Thakkar, S.; Ghebes, C. A.; Ahmed, M.; Kelder, C.; van Blitterswijk, C. A.; Saris, D.; Fernandes, H. A.; Moroni, L. Mesenchymal stromal cell-derived extracellular matrix influences gene expression of chondrocytes. Biofabrication 2013, 5 (2), 025003.

(31) Haynesworth, S. E.; Goshima, J.; Goldberg, V. M.; Caplan, A. I. Characterization of cells with osteogenic potential from human marrow. Bone 1992, 13 (1), 81-8.

(32) Lennon, D. P.; Haynesworth, S. E.; Bruder, S. P.; Jaiswal, N.; Caplan, A. I. Human and animal mesenchymal progenitor cells from bone marrow: Identification of serum for optimal selection and proliferation. In Vitro Cell. Dev. Biol.: Anim. 1996, 32 (10), 602-611.

(33) Ponticiello, M. S.; Schinagl, R. M.; Kadiyala, S.; Barry, F. P. Gelatin-based resorbable sponge as a carrier matrix for human mesenchymal stem cells in cartilage regeneration therapy. J. Biomed. Mater. Res. 2000, 52 (2), 246-255.

(34) Farndale, R. W.; Buttle, D. J.; Barrett, A. J. Improved Quantitation and Discrimination of Sulfated Glycosaminoglycans by Use of Dimethylmethylene Blue. Biochim. Biophys. Acta, Gen. Subj. 1986, 883 (2), 173-177.

(35) McGowan, K. B.; Kurtis, M. S.; Lottman, L. M.; Watson, D.; Sah, R. L. Biochemical quantification of DNA in human articular and septal cartilage using PicoGreen and Hoechst 33258. Osteoarthritis and cartilage/OARS, Osteoarthritis Research Society 2002, 10 (7), 580-7.

(36) Johnstone, B.; Alini, M.; Cucchiarini, M.; Dodge, G. R.; Eglin, D.; Guilak, F.; Madry, H.; Mata, A.; Mauck, R. L.; Semino, C. E.; Stoddart, M. J. Tissue engineering for articular cartilage repair-the state of the art. Eur. Cell Mater. 2013, 25, 248-67.

(37) Huey, D. J.; Hu, J. C.; Athanasiou, K. A. Unlike bone, cartilage regeneration remains elusive. Science 2012, 338 (6109), 917-21.

(38) Hoshiba, T.; Lu, H.; Yamada, T.; Kawazoe, N.; Tateishi, T.; Chen, G. Effects of extracellular matrices derived from different cell sources on chondrocyte functions. Biotechnol. Prog. 2011, 27 (3), 78895.

(39) Lu, H.; Hoshiba, T.; Kawazoe, N.; Koda, I.; Song, M.; Chen, G. Cultured cell-derived extracellular matrix scaffolds for tissue engineering. Biomaterials 2011, 32 (36), 9658-66.

(40) Tang, C.; Jin, C.; Xu, Y.; Wei, B.; Wang, L. Chondrogenic differentiation could be induced by autologous bone marrow mesenchymal stem cell-derived extracellular matrix scaffolds without exogenous growth factor. Tissue Eng., Part A 2016, 22 (3-4), 222-32. 
(41) Tang, C.; Jin, C.; Du, X.; Yan, C.; Min, B. H.; Xu, Y.; Wang, L. An autologous bone marrow mesenchymal stem cell-derived extracellular matrix scaffold applied with bone marrow stimulation for cartilage repair. Tissue Eng., Part A 2014, 20 (17-18), 2455-62.

(42) Lu, H.; Hoshiba, T.; Kawazoe, N.; Chen, G. Autologous extracellular matrix scaffolds for tissue engineering. Biomaterials 2011, 32 (10), 2489-99.

(43) Caplan, A. I. Mesenchymal stem cells. J. Orthop. Res. 1991, 9 (5), 641-50.

(44) Pittenger, M. F.; Mackay, A. M.; Beck, S. C.; Jaiswal, R. K.; Douglas, R.; Mosca, J. D.; Moorman, M. A.; Simonetti, D. W.; Craig, S.; Marshak, D. R. Multilineage potential of adult human mesenchymal stem cells. Science 1999, 284 (5411), 143-7.

(45) Yamamoto, M.; Ikada, Y.; Tabata, Y. Controlled release of growth factors based on biodegradation of gelatin hydrogel. $J$. Biomater. Sci., Polym. Ed. 2001, 12 (1), 77-88.

(46) Crapo, P. M.; Gilbert, T. W.; Badylak, S. F. An overview of tissue and whole organ decellularization processes. Biomaterials 2011, 32 (12), 3233-43.

(47) Revell, C. M.; Athanasiou, K. A. Success rates and immunologic responses of autogenic, allogenic, and xenogenic treatments to repair articular cartilage defects. Tissue Eng., Part B 2009, 15 (1), 1-15.

(48) Elder, B. D.; Eleswarapu, S. V.; Athanasiou, K. A. Extraction techniques for the decellularization of tissue engineered articular cartilage constructs. Biomaterials 2009, 30 (22), 3749-56.

(49) Cheng, H. W.; Tsui, Y. K.; Cheung, K. M.; Chan, D.; Chan, B. P. Decellularization of chondrocyte-encapsulated collagen microspheres: a three-dimensional model to study the effects of acellular matrix on stem cell fate. Tissue Eng., Part C 2009, 15 (4), 697-706.

(50) Gibson, M.; Li, H.; Coburn, J.; Moroni, L.; Nahas, Z.; Bingham, C., 3rd; Yarema, K.; Elisseeff, J. Intra-articular delivery of glucosamine for treatment of experimental osteoarthritis created by a medial meniscectomy in a rat model. J. Orthop. Res. 2014, 32 (2), 302-9.

(51) Varghese, S.; Theprungsirikul, P.; Sahani, S.; Hwang, N.; Yarema, K. J.; Elisseeff, J. H. Glucosamine modulates chondrocyte proliferation, matrix synthesis, and gene expression. Osteoarthritis Cartilage 2007, 15 (1), 59-68.

(52) Derfoul, A.; Miyoshi, A. D.; Freeman, D. E.; Tuan, R. S. Glucosamine promotes chondrogenic phenotype in both chondrocytes and mesenchymal stem cells and inhibits MMP-13 expression and matrix degradation. Osteoarthritis Cartilage 2007, 15 (6), 646-55.

(53) Bosnakovski, D.; Mizuno, M.; Kim, G.; Takagi, S.; Okumura, M.; Fujinaga, T. Chondrogenic differentiation of bovine bone marrow mesenchymal stem cells (MSCs) in different hydrogels: influence of collagen type II extracellular matrix on MSC chondrogenesis. Biotechnol. Bioeng. 2006, 93 (6), 1152-63.

(54) Rutgers, M.; Saris, D. B.; Vonk, L. A.; van Rijen, M. H.; Akrum, V.; Langeveld, D.; van Boxtel, A.; Dhert, W. J.; Creemers, L. B. Effect of collagen type I or type II on chondrogenesis by cultured human articular chondrocytes. Tissue Eng., Part A 2013, 19 (1-2), 59-65.

(55) Natoli, R. M.; Responte, D. J.; Lu, B. Y.; Athanasiou, K. A. Effects of multiple chondroitinase $\mathrm{ABC}$ applications on tissue engineered articular cartilage. J. Orthop. Res. 2009, 27 (7), 949-56.

(56) Jia, S.; Liu, L.; Pan, W.; Meng, G.; Duan, C.; Zhang, L.; Xiong, Z.; Liu, J. Oriented cartilage extracellular matrix-derived scaffold for cartilage tissue engineering. J. Biosci Bioeng 2012, 113 (5), 647-53.

(57) O’Brien, F. J.; Harley, B. A.; Yannas, I. V.; Gibson, L. J. The effect of pore size on cell adhesion in collagen-GAG scaffolds. Biomaterials 2005, 26 (4), 433-41.

(58) Haugh, M. G.; Murphy, C. M.; McKiernan, R. C.; Altenbuchner, C.; O'Brien, F. J. Crosslinking and mechanical properties significantly influence cell attachment, proliferation, and migration within collagen glycosaminoglycan scaffolds. Tissue Eng., Part A 2011, 17 (9-10), 1201-1208.

(59) Goetsch, K. P.; Bracher, M.; Bezuidenhout, D.; Zilla, P.; Davies, N. H. Regulation of tissue ingrowth into proteolytically degradable hydrogels. Acta Biomater. 2015, 24, 44-52.

(60) Wendt, D.; Stroebel, S.; Jakob, M.; John, G. T.; Martin, I. Uniform tissues engineered by seeding and culturing cells in $3 \mathrm{D}$ scaffolds under perfusion at defined oxygen tensions. Biorheology 2006, 43 (3-4), 481-8.

(61) Ramirez, F.; Rifkin, D. B. Cell signaling events: a view from the matrix. Matrix Biol. 2003, 22 (2), 101-7.

(62) Lee, K.; Silva, E. A.; Mooney, D. J. Growth factor delivery-based tissue engineering: general approaches and a review of recent developments. J. R. Soc., Interface 2011, 8 (55), 153-70.

(63) Widuchowski, W.; Widuchowski, J.; Trzaska, T. Articular cartilage defects: study of 25,124 knee arthroscopies. Knee 2007, 14 (3), 177-82.

(64) Madry, H.; Rey-Rico, A.; Venkatesan, J. K.; Johnstone, B.; Cucchiarini, M. Transforming growth factor Beta-releasing scaffolds for cartilage tissue engineering. Tissue Eng., Part B 2014, 20 (2), 10625.

(65) Kim, M.; Erickson, I. E.; Choudhury, M.; Pleshko, N.; Mauck, R. L. Transient exposure to TGF-beta3 improves the functional chondrogenesis of MSC-laden hyaluronic acid hydrogels. J. Mech Behav Biomed Mater. 2012, 11, 92-101.

(66) Gadjanski, I.; Spiller, K.; Vunjak-Novakovic, G. Time-dependent processes in stem cell-based tissue engineering of articular cartilage. Stem Cell Rev. 2012, 8 (3), 863-81. 